\title{
Salts, Cocrystals and Ionic Cocrystals of a "Simple" Tautomeric Compound
}

DOI:

10.1021/acs.cgd.8b01159

\section{Document Version}

Accepted author manuscript

Link to publication record in Manchester Research Explorer

\section{Citation for published version (APA):}

Wang, T., Stevens, J. S., Vetter, T., Whitehead, G., Vitorica-Yrezabal, I., Hao, H., \& Cruz-Cabeza, A. J. (2018). Salts, Cocrystals and lonic Cocrystals of a "Simple" Tautomeric Compound. Crystal Growth and Design. https://doi.org/10.1021/acs.cgd.8b01159

\section{Published in:}

Crystal Growth and Design

\section{Citing this paper}

Please note that where the full-text provided on Manchester Research Explorer is the Author Accepted Manuscript or Proof version this may differ from the final Published version. If citing, it is advised that you check and use the publisher's definitive version.

\section{General rights}

Copyright and moral rights for the publications made accessible in the Research Explorer are retained by the authors and/or other copyright owners and it is a condition of accessing publications that users recognise and abide by the legal requirements associated with these rights.

\section{Takedown policy}

If you believe that this document breaches copyright please refer to the University of Manchester's Takedown Procedures [http://man.ac.uk/04Y6Bo] or contact uml.scholarlycommunications@manchester.ac.uk providing relevant details, so we can investigate your claim.

\section{OPEN ACCESS}




\section{Salts, Cocrystals and Ionic Cocrystals of a "Simple" Tautomeric \\ Compound}

Ting Wang ${ }^{\text {a, b }}$, Joanna S. Stevens ${ }^{\text {c,d }}$, Thomas Vetter ${ }^{\mathrm{d}}$, George F. S. Whitehead ${ }^{\mathrm{e}}$, Iñigo J. Vitorica-Yrezabal ${ }^{\mathrm{e}}$, Hongxun Hao ${ }^{\mathrm{a}, \mathrm{b}}$, Aurora J. Cruz-Cabeza ${ }^{\mathrm{d}, *}$

a State Key Laboratory of Chemical Engineering, School of Chemical Engineering and Technology, Tianjin University, Tianjin 300072, P. R. China

b Collaborative Innovation Center of Chemical Science and Chemical Engineering, Tianjin 300072, P. R. China

c Cambridge Crystallographic Data Centre, 12 Union Road, Cambridge, CB2 1EZ, United Kingdom

d School of Chemical Engineering and Analytical Science, University of Manchester, M13 9PL Manchester, United Kingdom

e School of Chemistry, University of Manchester, M13 9PL Manchester, United Kingdom

Corresponding author: aurora.cruzcabeza@manchester.ac.uk 


\begin{abstract}
We have investigated the cocrystallisation behaviour of AHMP (2-amino-6-methyl-1,4-dihydropyrimidin-4-one) with a series of acids and imide coformers. Being a base able to tautomerise, at the molecular level, AHMP may exist as three different neutral tautomers or, if protonated, in the form of several cationic species. Crystal engineering concepts were used in order to attempt selective isolation of several tautomers. For this, a series of acids and imides were used as coformers. Cocrystallisation with acids resulted in eleven new solid forms including salts, ionic cocrystals and cocrystals. Cocrystallisations with imides did not afford any new forms, while cocrystallisation with saccharin afforded two polymorphic salts and an ionic cocrystal. Two of the possible tautomers were obtained as well as one of the cationic species. DFT calculations were carried out in order to rationalize the molecular species obtained as well as the supramolecular motifs. Despite being a small "simple" molecule, AHMP has a very rich and interesting solid form landscape with cocrystals containing two different tautomers, many salts (some of which are polymorphic) and multiple ionic cocrystals.
\end{abstract}

Key words: Tautomerism; Cocrystals; Salts; Ionic Cocrystals; XPS; 


\section{Introduction}

In the solid state, active pharmaceutical ingredients (APIs) can be amorphous or crystallise in a diverse range of forms (i.e. neat forms, solvates, cocrystals, salts...). It is well-documented that different crystalline forms of APIs have different physicochemical and pharmacokinetic properties such as solubility, stability, bioavailability or manufacturability ${ }^{1-5}$. Some solid forms of APIs can present solubility or stability issues; this problem may be solved through the design of salts and cocrystals, with improved and tailored physicochemical properties ${ }^{6-10}$. The selection of cocrystal formers and salt counterions that will afford new forms of a given API, however, is not straightforward. Nonetheless, hydrogen bond complementarity ${ }^{11,12}$ as well as molecular shape seem to be factors ${ }^{13}$ which favour cocrystal formation. A basic API may crystallise as a salt in combination with a strong acid. If a weaker acid is used instead, a salt, a cocrystal or an intermediate complex (salt-cocrystal continuum) may be obtained ${ }^{14}$. Unpredictability arises around whether proton transfer occurs if the basicity of the API and the acidity of the cofomer are comparable (quantified as the difference between the $\mathrm{p} K_{\mathrm{a}}$ of the protonated API and the acid being larger than 0 but less than $4^{16-19}$ ). Further to these, ionic cocrystals (ICs) are an old yet underexplored type of multicomponent crystals which have attracted increasing attention in recent years; ${ }^{15}$ in ICs, a cation, anion and a neutral molecule crystallise together in a unique crystal structure. ICs offer the advantage of a) an increase diversity since three different components are introduced in a lattice (rather than two as in salts and cocrystals) and b) a new set of materials and properties to explore.

Beyond the protonation uncertainties associated with salt/cocrystal formation, compounds able to tautomerise may exhibit even more complex behaviour in the solid-state. ${ }^{20-22}$ Tautomers are isomers of a compound related by the migration of a proton within the molecule. Because of their inherent structural variations, tautomers may show striking differences in their chemical as well as physical properties such as hydrophobicity, polarity ${ }^{23}$ and even colour. ${ }^{24}$ They may also be able to form very distinct and different intermolecular interactions. Whilst the different tautomers of a molecule are in equilibrium in solution, which is governed by the relative stabilities of the tautomers in a given solvent, ${ }^{25}$ they are often 
isolated in their most stable tautomer in the solid state. ${ }^{26,27}$ However, there are examples of higher energy tautomers in various crystalline forms. ${ }^{28-31}$ Isolating unstable tautomers in the solid state can be challenging (i.e. barbituric acid) ${ }^{32}$ but it is (in cases) achievable through targeted cocrystal design. ${ }^{33-34}$ Since tautomers are structurally different, different coformers may be able to selectively interact with different tautomeric forms. This strategy has been successfully used in the past to make new cocrystals of unstable tautomers. ${ }^{35-39}$ For example, Kanishka et al. successfully isolated both stable and metastable tautomers of 1-deazapurine making use of coformers able to form selective supramolecular synthons with the different tautomeric forms. ${ }^{40}$ Thus, to efficiently generate multi-component systems which stabilize high-energy tautomer molecules, it is of fundamental importance to analyse the tautomer transformation in different cocrystals and salts, by evaluating how molecules interact with each other as well as identifying dominant supramolecular synthons. Being able to engineer crystal structure together with tautomeric structure, thus, will enable the design of new solid forms with a range of new physicochemical properties.

We are interested in a pyrimidone-based drug intermediate used for the treatment of trypanosomiasis in animals (a parasitic disease). We refer to our compound in all of its molecular forms as AHMP. AHMP can exist in three different tautomeric forms (Figure 1): tautomer A (2-amino-6-methyl-1,4-dihydropyrimidin-4-one), tautomer B (2-amino-6-methyl-3,4-dihydropyrimidin-4-one) and tautomer C (2-amino-4-hydroxy-6-methylpyrimidine). Tautomers A and B are keto tautomers whilst tautomer $\mathrm{C}$ is a enol tautomer. AHMP can also be protonated in the presence of a medium-strong acid, three main cations may occur: the $\mathrm{A}^{+} / \mathrm{B}^{+}$which would result from protonation of either the A or B tautomers, and the $\mathrm{C}^{+}$and $\mathrm{C}^{+}$cations which would result from protonation of the $\mathrm{N} 1$ or $\mathrm{N} 3$ nitrogen atoms of tautomer $\mathrm{C}$, respectively. 


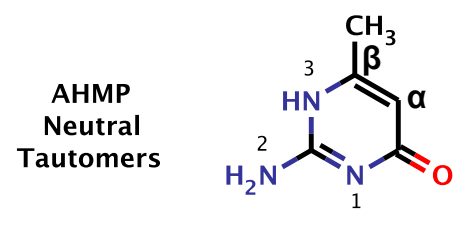

A

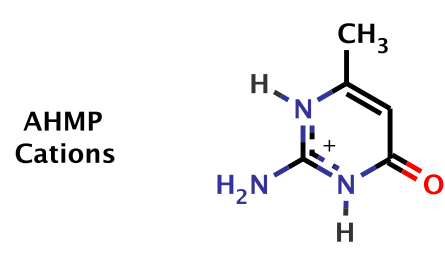

$\mathbf{A}^{+} / \mathbf{B}^{+}$<smiles>Cc1cc(=O)[nH]c(N)n1</smiles>

B<smiles></smiles>

$\mathrm{C}^{+}$<smiles>Cc1cc(O)nc(N)n1</smiles>

C<smiles>Cc1cc(O)nc(N)[nH+]1</smiles>

$\mathrm{C3}^{+}$

Figure 1. Tautomers $(\mathrm{A}, \mathrm{B}, \mathrm{C})$ and cations $(\mathrm{A}+, \mathrm{C} 1+, \mathrm{C} 3+)$ of $\mathrm{AHMP}$.

While increasing interests have been shown on AHMP-based tautomeric diversity in different multi-component systems, to the best of our knowledge, efforts have merely been confined to structural investigations. The generation of new multicomponent systems of AHMP and an analysis and discussion on tautomer and cationic species in them is the subject of the current study. Given the fascinating molecular structure diversity of AHMP (Figure 1), an investigation of whether or not all these species can be isolated in the solid state and how intermolecular interactions may impact the molecular structure has driven the current research. Beyond the fundamental nature of the current research, our approach may prove valuable for solid form discovery of other APIs able to tautomerise. For this paper, we first analysed the CSD for tautomeric diversity of similar compounds and computed the stability of the different molecular species of AHMP. We then carried out a series of grinding and solution crystallisation experiments with 15 different cocrystal formers. From this, we have obtained 11 new solid forms for AHMP revealing a very rich solid form landscape for this "simple" compound, with complex behavior at the molecular level. 


\section{Methods}

\section{Materials and experimental methods}

AHMP (purity 98\%, tautomer A), the coformers listed in Figure 4, and solvents (methanol, ethanol, iso-propanol, DMF, DMSO, acetone, acetonitrile) were purchased from Sigma-Aldrich and used without further purification. Where crystallisation experiments were carried out in water as a solvent, deionized and filtered water (ASTM D1193-91 Type I) was used.

\section{Grinding experiments.}

At the beginning of the experimental campaign liquid-assisted grinding (LAG) processes were conducted with various solvents and coformers (see table 3). Equimolar amounts of AHMP and the respective coformer were weighed and put in a $5 \mathrm{~mL}$ stainless steel cell with addition of a drop of solvent. Solvents used in the LAG included methanol, ehtanol, DMSO, acetone, acetonitrile and ethyl acetate. The samples were ground with a stainless steel ball (7 mm diameter) using a Retsch MM200 mixer mill at $25 \mathrm{~Hz}$ for $20 \mathrm{~min}$. The resulting products were analysed by power X-ray diffraction (PXRD) with the aim of identifying new forms. If a new form was produced by grinding, cocrystallisation from solution was then attempted.

\section{Cocrystallisation experiments from solution.}

For cooling crystallisations, the necessary amounts ( 100-200 mg) of AHMP and conformer $(\sim 100-200 \mathrm{mg})$ in $1: 1$ or $2: 1$ molar ratios were dissolved in $\sim 30 \mathrm{~mL}$ of water at $40{ }^{\circ} \mathrm{C}$ and then cooled down to $10{ }^{\circ} \mathrm{C}$ at a rate of $0.5^{\circ} \mathrm{C} / \mathrm{h}$.

For slow evaporation, the necessary amounts of AHMP:conformer in 1:1 or 2:1 molar ratios were dissolved in water $(\sim 30 \mathrm{ml})$ or methanol $(\sim 50 \mathrm{ml})$ at room temperature and were subsequently left to evaporate at room conditions. After 7 days, crystals suitable for single crystal XRD were obtained. Further details on the cocrystallisation experiments are given in the ESI.

\section{Powder X-ray diffraction (PXRD) analysis}


All the samples were first analysed by powder X-ray diffraction using a Rigaku D/MAX 2500 diffractometer $(\mathrm{Cu} \mathrm{K \alpha}$ radiation $0.15418 \mathrm{~nm})$. The range of scanning angle was from $2^{\circ}$ to $40^{\circ}$ at a rate of $8^{\circ} \mathrm{min}^{-1}$, with current of $100 \mathrm{~mA}$ and a voltage of $40 \mathrm{kV}$. All the data were analyzed using the commercial software JADE (version 7.0, Materials Data, Inc., Livermore, CA).

\section{Single crystal X-ray diffraction (SCXRD) analysis}

Single crystal XRD was performed on a Rigaku Oxford Diffraction FR-X DW diffractometer equipped with a selectable dual wavelength ( $\operatorname{MoK} \alpha \lambda=0.71073 \AA$ and $\operatorname{CuK} \alpha \lambda=1.5418 \AA$ ) rotating anode system VarimaxTM microfocus optics. Rigaku Oxford Diffraction CrysAlisPro ${ }^{41}$ was used for data collection and cell refinement, and the structures were solved and refined by using SHELX-2014. ${ }^{42}$ Most hydrogen atoms were assigned idealized positions and were included in structure factor calculations. All non-hydrogen atoms were refined anisotropically.

\section{Differential scanning calorimetry (DSC) \& Thermogravimetric (TG) analysis}

All the samples were further identified by DSC which had been calibrated with indium and zinc standards (Mettler Toledo DSC 1/500). Powder samples (5-10 mg) were accurately weighed and put in an aluminum pan and then was sealed with a cover. The samples were heated from 25 to $350^{\circ} \mathrm{C}$ at a rate of $10^{\circ} \mathrm{C} / \mathrm{min}$. TG analysis (Mettler Toledo TGA) was carried out using similar amounts of sample in aluminium oxide pans, and identical heating procedure as in DSC.

\section{X-ray photoelectron spectroscopy (XPS)}

XPS spectra of the powder samples $(\sim 1 \mathrm{mg})$ were recorded with a Kratos Axis Ultra instrument employing a monochromatic $\mathrm{Al} \mathrm{K \alpha}$ source $(1486.69 \mathrm{eV})$ at $10^{-8}$ mbar. ${ }^{43}$ High resolution spectra were obtained within the spectral range of interest (ca. $\pm 20 \mathrm{eV}$ around the core level emission peaks) with $0.1 \mathrm{eV}$ steps and $1000 \mathrm{~ms}$ dwell time per data point. Analysis of the data was carried out with CasaXPS software using a linear background and GL (30) line shape $(70 \%$ Gaussian, $30 \%$ Lorentzian $) ;{ }^{44}$ core level binding energies for the three 
nitrogen atoms in the tautomers and cationic forms of AHMP were calculated using DFT (see below) to confirm the chemical shift order of N1, N2 and N3 by comparing the relative order of core level binding energies for the three nitrogen atoms. Samples were referenced to the lowest $E_{\mathrm{B}}$ component $\mathrm{C}=\mathrm{C}$ at $284.8 \mathrm{eV}$, and repeatability of the peak positions was within 0.1 eV. XPS was measured for all systems except those exhibiting unfavourably high vapour pressures.

The schematic representation of the tautomeric and cationic forms of AHMP was constructed using the chemical shifts of the component peaks for the experimental data of tautomer A, tautomer B (AHMP:glutaric cocrystal) and the $\mathrm{A}^{+} / \mathrm{B}^{+}$cation (AHMP: $\mathrm{HCl}$ salt) relative to that of $\mathrm{N} 2$ of tautomer $\mathrm{A}$, using peak widths of tautomer $\mathrm{A}$ and cation $\mathrm{A}^{+} / \mathrm{B}^{+}$, respectively. The spectrum for tautomer $\mathrm{C}$ was extrapolated based on knowledge of the chemical structure and associated positions for different chemical environments observed in the other tautomeric forms.

\section{Molecular Simulations}

AHMP tautomers (A, B and C) and the cationic forms $\left(\mathrm{A}^{+} / \mathrm{B}^{+}, \mathrm{Cl}^{+}\right.$, and $\left.\mathrm{C}^{+}\right)$were optimised with density functional theory (DFT) at the M06/6-31+G(d,p) level of theory using Gaussian $09^{45}$ in the gas-phase. From these calculations, ground-state core level binding energies for the three nitrogen atoms N1, N2 and N3 were calculated ${ }^{46,47}$ Further to this, the tautomers were also optimized making use of an SMD solvation model ${ }^{48}$ for various solvent environments. The stabilities of tautomers were then calculated in each solvent environment relative to the most stable tautomeric form $\left(\Delta \mathrm{E}_{\text {tau }}\right)$. Finally, selective dimers were also optimized in the gas-phase and the continuum solvation models using the same levels of theory. Dimerisation energies was calculated as the difference between the electronic energy of the dimer and that of the isolated monomers. The reported overall stability of dimers was calculated as $\mathrm{E}_{\text {dimer-stability }}=\mathrm{E}_{\text {dimerisation }}-\Delta \mathrm{E}_{\text {tau }}$.

\section{Results and Discussion}

\subsection{CSD survey of structures containing AHMP-like structures}

A detailed search of pyrimidinone derivatives and its tautomers and charged species was 
performed in the Cambridge Structural Database (CSD). For this, a substructure search of AHMP allowing any type of substituents in the $\alpha$ and $\beta$ carbon atoms was used (Figure 1). The CSD search revealed that tautomer B is clearly the most commonly observed tautomer (173 hits) followed by structures containing A:B dimers and structures with tautomer A alone (Table 1). Tautomer $\mathrm{C}$ is reported in two crystal structures (CSD refcodes DGUBCY ${ }^{49}$ and GEZQAD ${ }^{50}$ ), although judging by the unphysical contacts shown in the structure these structures are likely to have misdetermined hydrogen atom positions. Of the 19 salt structures in the $\mathrm{CSD}$, all of them contained the $\mathrm{A}^{+} / \mathrm{B}^{+}$species. Additionally, four ionic cocrystals involving $\mathrm{A}: \mathrm{B}^{+}$dimers were found and two cocrystals with $\mathrm{A}: \mathrm{B}^{+/}$. In the latter case, the molecule was able to form a zwiterionic form $\left(\mathrm{B}^{+-}\right)$in which the AHMP ring was protonated and an acid group elsewhere in the molecule deprotonated (see refcodes ZERMUE and ZERNEP) ${ }^{51}$ It is important to highlight that some of the CSD structures had some resolved disorder in proton positions. The high H-bond complementarity between tautomer A and B (Figure 2) makes the observation of $\mathrm{A}: \mathrm{B}$ and $\mathrm{A}: \mathrm{B}^{+}$dimers very common (Table 1).

Table 1. Summary of CSD observations of crystals containing various AHMP species.

\begin{tabular}{|c|c|c|}
\hline \multirow{2}{*}{ Crystals with Neutral Species } & & Number of CSD observations \\
\cline { 2 - 3 } & $\mathbf{A}$ & 6 \\
\cline { 2 - 3 } & $\mathbf{B}$ & 173 \\
\cline { 2 - 3 } & $\mathbf{A}: \mathbf{B}$ & 11 \\
\hline \multirow{2}{*}{ Salts } & $\mathbf{A}^{+} / \mathbf{B}^{+}$ & $2^{*}$ \\
\cline { 2 - 3 } & $\mathbf{C 1}^{+}$ & 19 \\
\cline { 2 - 3 } & $\mathbf{C 3}^{+}$ & 0 \\
\hline Ionic Cocrystals & $\mathbf{A : B}^{+}$ & 0 \\
\hline Cocrystal with zwitterion & $\mathbf{A : B}^{+/-}$ & 4 \\
\hline
\end{tabular}

*Structures probably contain errors in the determination of $\mathrm{H}$ atom positions as the structures show unusual intramolecular geometries or intermolecular contacts.
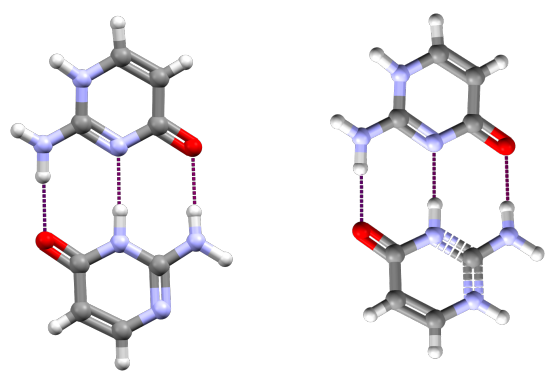
Figure 2. H-bond complementarity between tautomer $\mathrm{A}$ and $\mathrm{B} / \mathrm{B}^{+}$results in strong $\mathrm{A}: \mathrm{B}$ (left) and $\mathrm{A}: \mathrm{B}^{+}$ dimers (right).

\subsection{Relative stabilities of the tautomers}

The relative stabilities of the tautomers and cationic species of AHMP in the gas phase, chloroform and water as computed with DFT (see above) are reported in Table 2. The relative stability of the tautomers is strongly dependent on the solvent environment. For example, tautomer $\mathrm{C}$ is the lowest energy tautomer in the gas-phase but the highest energy in water. Similarly, whilst A is the highest energy tautomer in the gas-phase, it is low energy in water. $\mathrm{B}$ is the lowest energy tautomer in the tested solution environments, which is congruent with the fact that it is the tautomer observed most frequently in organic crystal structures in the CSD. For the cations, the $\mathrm{A}^{+} / \mathrm{B}^{+}$species are the most stable species in water, while they exhibit similar energies to the lowest energy species, $\mathrm{C}^{+}$, in chloroform. $\mathrm{C}^{+}$is also the most stable cationic species in the gas phase with the other species at high $\Delta E_{\text {tau. }}$ Therefore, $\mathrm{A}^{+} / \mathrm{B}^{+}$are always similar in energy in environments other than the gas-phase (which is an unrealistic scenario for charged species). Thus, we notice that there is generally good agreement between the low energy species reported in Table 2 and those most commonly observed in the CSD (see Table 1; with the expection of the $\mathrm{C}^{+}$species).

Table 2 Summary of relative stabilities of tautomers and cations of AHMP.

\begin{tabular}{|c|c|c|c|c|}
\hline \multirow{2}{*}{} & \multicolumn{3}{|c|}{ Relative energy (kJ/mol) } \\
\cline { 2 - 5 } & Gas & Chloroform & Water \\
\hline \multirow{2}{*}{$\begin{array}{c}\text { Neutral } \\
\text { Tautomers }\end{array}$} & A & 51.6 & 23.8 & 5.3 \\
\cline { 2 - 5 } & $\mathbf{B}$ & 6.6 & 0.0 & 0.0 \\
\cline { 2 - 5 } & $\mathbf{C}$ & 0.0 & 11.2 & 20.5 \\
\hline \multirow{2}{*}{ Cations } & $\mathbf{A}^{+} / \mathbf{B}^{+}$ & 34.8 & 1.6 & 0.0 \\
\cline { 2 - 5 } & $\mathbf{C 1}^{+}$ & 31.0 & 29.8 & 34.0 \\
\cline { 2 - 5 } & $\mathbf{C 3}^{+}$ & 0.0 & 0.0 & 7.8 \\
\hline
\end{tabular}

\subsection{Strategy for the formation of multicomponent crystals}

For the design of our cocrystallisation experiments we used crystal engineering principles of H-bond complementarity. We chose a series of organic acids, since we envisage strong synthons to form with either tautomer A or B (Figure 3). ${ }^{[52]}$ Since tautomer B is the most 
stable tautomer, we expect tautomer B to dominate because of intramolecular energy alone, but tautomer A complexes may also form. In addition to the acids, we also chose a series of imides and saccharin, in an attempt to produce tautomer $\mathrm{C}$ of our compound (which has never been observed before and is a high energy tautomer, cf. Table 2). We expect that imides may form very strong dimers with tautomer $\mathrm{C}$ through the formation of three $\mathrm{H}$-bonds (Figure 3). The molecular structures of all coformers are given in Figure 4.

A<smiles></smiles>

B

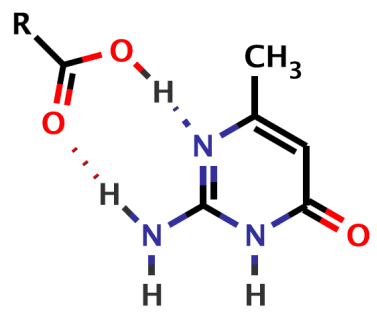

C

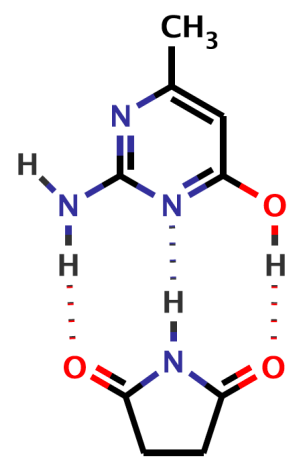

Figure 3. Envisioned synthons for acid coformers interacting with tautomer A (left), acid coformers interacting with tautomer B (centre) and imide coformer interacting with tautomer C (right).

In order to anticipate whether some of the acids used would form salts rather than cocrystals according to the $\Delta \mathrm{p} K_{\mathrm{a}}$ rule, we measured the $\mathrm{p} K_{\mathrm{a}}$ of our compound to be 4.20 (for the protonated base, see Figure S4 in the ESI) through a titration experiment (with $\mathrm{HCl}$ ). In doing so, we also obtained a $\mathrm{HCl}$ salt and a hydrated ionic cocrystal of AHMP, which is also reported in this study. As the $\Delta \mathrm{p} K_{\mathrm{a}}$ between AHMP and our chosen acids lie between - 0.6 and 3 (cf. Table 4), we can expect cocrystals, salts and even ionic cocrystals to occur for all of our selected acids. Saccharin is also a strong acid $\left(\mathrm{p} K_{\mathrm{a}}=1.6\right)$, significantly stronger than imides ( $K_{\mathrm{a}} \sim 9$ ), thus salt formation may also be possible for saccharin. 


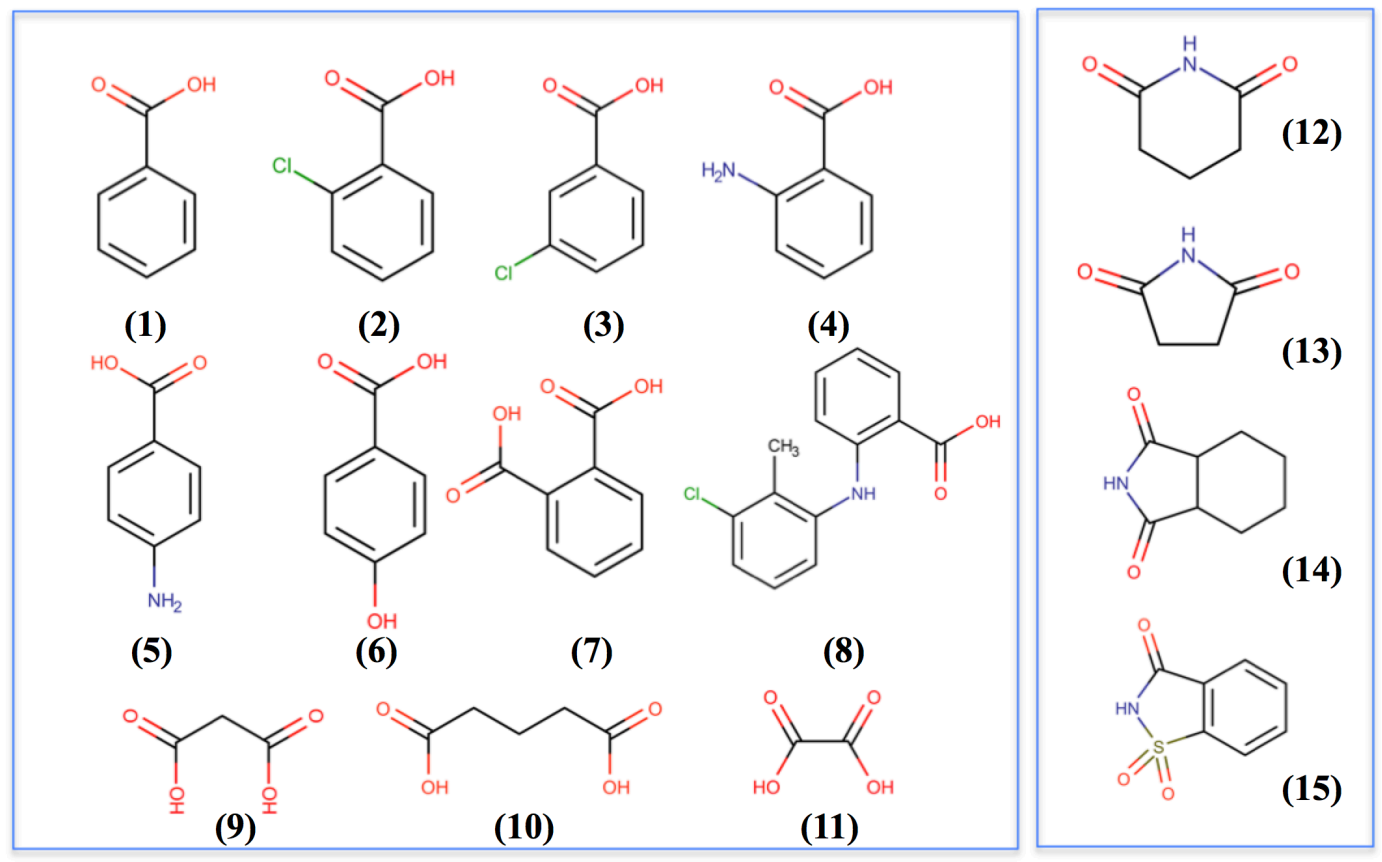

Figure 4. Molecular structure of the 15 coformers used in this study.

\subsection{New crystalline forms discovered}

Multicomponent crystal formation with AHMP and the targeted coformers was first attempted by liquid assisted grinding (LAG). Ground products were then analysed with PXRD to check whether or not a new phase was formed. All new forms obtained had distinct PXRD patterns different from the starting materials (see Figure S1 in the ESI), with unique DSC \& TG thermographs (see Figure S2 \& S3 in the ESI).

After new forms were generated in grinding experiments and identified by PXRD, the growth of single crystals of the new forms were attempted from methanol or water (See Table S1 in detail). Saturated solutions of AHMP and the desired coformers were prepared after which they were seeded with the new forms obtained by grinding. A summary of the results is given in Table 3. Of the 15 coformers attempted, AHMP formed new forms with 11 of them. All of the acids used as coformers in this study, with the exception of tolfenamic acid, (8), and 3-chlorobenzoic acid, (3), formed new multicomponent structures. In contrast, among the imides, only cocrystallisation with saccharin resulted in a new form, with three new forms discovered for AHMP and saccharin. 
Table 3. Summary of the salt/cocrystals obtained with the 18 different salt and cocrystal formers.

\begin{tabular}{|c|c|c|c|}
\hline $\begin{array}{c}\text { Coformer } \\
\text { No. }\end{array}$ & Coformers & New Forms & Single Crystals \\
\hline$(1)$ & HCl & $\checkmark$ & $\checkmark$ \\
\hline$(2)$ & 2-Chlorobenzoic acid & $\checkmark$ & $\checkmark$ \\
\hline$(3)$ & 3-Chlorobenzoic acid & $x$ & $x$ \\
\hline$(4)$ & Anthranilic acid & $\checkmark$ & $x$ \\
\hline$(5)$ & p-aminobenzoic acid & $\checkmark$ & $\checkmark$ \\
\hline$(6)$ & 4-hydroxybenzoic acid & $\checkmark$ & $x$ \\
\hline$(7)$ & Phthalic acid & $\checkmark$ & $\checkmark$ \\
\hline$(8)$ & Tolfenamic acid & $x$ & $x$ \\
\hline$(9)$ & Malonic acid & $\checkmark$ & $\checkmark$ \\
\hline$(10)$ & Glutaric acid & $\checkmark$ & $\checkmark$ \\
\hline$(11)$ & Oxalic Acid & $\checkmark$ & $\checkmark$ \\
\hline$(12)$ & Glutarimide & $x$ & $x$ \\
\hline$(13)$ & Succinimide & $x$ & $x$ \\
\hline$(14)$ & cis-hexahydrophthalimide & $x$ & $x$ \\
\hline$(15)$ & Saccharin & $\checkmark$ & $\checkmark$ \\
\hline
\end{tabular}

After the grinding and cocrystallisation experiments, we were able to obtain single crystals for twelve forms obtained from nine different coformers. Their structures were determined by single crystal XRD analysis, which led to the discovery of eleven new structures and a cocrystal that was previously reported (AHMP: glutaric acid cocrystal, CSD refcode: ZUKXAE ${ }^{53}$ ). A summary of all of newly deteemined structures together with AHMP multicomponent crystals previously available in the CSD, is given in Table 4 (19 entries in total). We also record the nature of the tautomer or the cation in the different forms obtained as well as their stoichiometry and the acidity of the coformer and $\Delta \mathrm{p} K_{\mathrm{a}}$.

The eleven newly discovered forms of AHMP include: i) three new salts with $\mathrm{HCl}$, oxalic acid and phthalic acid, ii) a hydrate salt with saccharin which was found to be polymorphic (forms I \& II), iii) two ionic cocrystals with saccharin and malonic acid, iv) a hydrate of an ionic cocrystal of malonic acid, as well as $\mathrm{HCl}, \mathrm{v})$ two cocrystals with p-aminobenzoic acid (pABA) and benzoic acid. 
Table 4. List of salts, cocrystals and ionic cocrystals containing AHMP.

\begin{tabular}{|c|c|c|c|c|c|c|c|}
\hline $\begin{array}{c}\text { Acid } \\
\mathrm{p} K_{\mathrm{a}}\end{array}$ & $\Delta \mathrm{p} K_{\mathrm{a}}$ & $\begin{array}{l}\text { Crystal } \\
\text { Type* }\end{array}$ & $\begin{array}{c}\text { Tautom } \\
\text { er }\end{array}$ & Water & Refcode & Coformer / Solvent & $\begin{array}{l}\text { Composition }^{* *} \\
\text { (Stoichiometry) }\end{array}$ \\
\hline-15.2 & 19.4 & IC & $\mathrm{A}: \mathrm{B}^{+}$ & Yes & EXIPOR & Perchloric acid & $\mathrm{A}: \mathrm{A}^{+}: \mathrm{X}^{-}: \mathrm{W}(1: 1: 1: 1)$ \\
\hline-7.0 & 11.2 & Salt & $\mathbf{A}^{+}$ & - & This study & Hydrochloric acid & $A^{+}: X^{-}(1: 1)$ \\
\hline-7.0 & 11.2 & $\mathrm{IC}^{\S}$ & $\mathrm{A}: \mathrm{B}^{+}$ & Yes & This study & Hydrochloric acid & $A: B^{+}: X^{-}: W(3: 1: 1: 5)$ \\
\hline 1.3 & 2.9 & Salt & $\mathbf{A}^{+}$ & Yes & This study & Oxalic acid & $A^{+}: X^{-}: W(1: 1: 1)$ \\
\hline 1.6 & 2.6 & Salt & $\mathbf{A}^{+}$ & Yes & $\begin{array}{c}\text { This study, } \\
\text { Form I } \\
\end{array}$ & Saccharin & $A^{+}: X^{-}: W(1: 1: 1)$ \\
\hline 1.6 & 2.6 & Salt & $\mathbf{A}^{+}$ & Yes & $\begin{array}{c}\text { This study, } \\
\text { Form II }\end{array}$ & Saccharin & $A^{+}: X^{-}: W(1: 1: 1)$ \\
\hline 1.6 & 2.6 & IC & $A: B^{+}$ & - & This study & Saccharin & $A: B^{+}: X^{-}(1: 1: 1)$ \\
\hline 2.2 & 2.0 & IC & $\mathrm{A}: \mathrm{B}^{+}$ & - & MINVIP & Phosphoric acid & $\mathrm{A}: \mathrm{B}^{+}: \mathrm{X}^{-}(1: 1: 1)$ \\
\hline 2.2 & 2.0 & IC & $\mathrm{A}: \mathrm{B}^{+}$ & - & MINVIP 01 & Phosphoric acid & $\mathrm{A}: \mathrm{B}^{+}: \mathrm{X}^{-}(1: 1: 1)$ \\
\hline 2.2 & 2.0 & Salt & $\mathrm{A}^{+}$ & - & XOWKOK & Phosphoric acid & $\mathrm{A}^{+}: \mathrm{X}^{-}(1: 1)$ \\
\hline $2.5^{\S}$ & 1.7 & Salt & $\mathrm{A}^{+}$ & Yes & YOCZUN & $\begin{array}{c}\text { 2,3,5,6-tetrafluorote } \\
\text { rephthalic acid }\end{array}$ & $\mathrm{A}^{+}: \mathrm{X}^{2-}: \mathrm{W}(2: 1: 1)$ \\
\hline 2.8 & 1.4 & IC & $\mathrm{A}: \mathrm{B}^{+}$ & - & This study & Malonic Acid & $\mathrm{A}: \mathrm{B}^{+}: \mathrm{X}^{-}(1: 1: 1)$ \\
\hline 2.8 & 1.4 & IC & $\mathrm{A}: \mathrm{B}^{+}$ & Yes & This study & Malonic Acid & $\mathrm{A}: \mathrm{B}^{+}: \mathrm{X}^{-}: \mathrm{W}(1: 1: 1: 1)$ \\
\hline 2.9 & 1.3 & Salt & $\mathbf{A}^{+}$ & - & This study & Phthalic acid & $\mathbf{A}^{+}: \mathbf{X}^{-}$ \\
\hline $4.0^{\S}$ & 0.2 & IC & $\mathrm{A}: \mathrm{B}^{+}$ & Yes & VAJPII & $\begin{array}{c}\text { 6-Hydroxy-2-naphth } \\
\text { oic acid }\end{array}$ & $\begin{array}{c}\mathrm{A}: \mathrm{B}^{+}: \mathrm{X}^{-}: \mathrm{W} \\
(1: 1: 1: 1)\end{array}$ \\
\hline 4.2 & 0.0 & Cocrystal & $\mathbf{A}$ & - & This study & Benzoic Acid & $A: X(1: 1)$ \\
\hline 4.3 & -0.1 & Cocrystal & $\mathrm{B}$ & - & ZUKXEI & Adipic acid & $\mathrm{B}: \mathrm{X}(1: 1)$ \\
\hline 4.4 & -0.2 & Cocrystal & B & - & $\begin{array}{l}\text { ZUKXAE / } \\
\text { This study }\end{array}$ & Glutaric acid & $\mathrm{B}: \mathrm{X}(1: 1)$ \\
\hline 4.8 & -0.6 & Cocrystal $^{\mathbb{f}}$ & B & Yes & This study & pABA & B:X:W (1:1:1) \\
\hline
\end{tabular}

${ }^{*} \mathrm{IC}=$ Ionic Cocrystal. ${ }^{* *} \mathrm{~A}$ and $\mathrm{B}$ refer to the tautomers, $\mathrm{X}=$ coformer/counterion and

$\mathrm{W}=$ water. ${ }^{\S}$ Calculated with ChemAxon. ${ }^{\S}$ The structure is disordered. "Proton disorder found

in SC-XRD

Note that all coformers with $\mathrm{p} K_{\mathrm{a}}<4.2$ result in multicomponent structures which involved proton transfer to AHMP. Of those 14 structures in table 4, 50\% of them are ionic cocrystals containing the strong $\mathrm{A}: \mathrm{B}^{+}$dimer whilst the other $50 \%$ form salts of $\mathrm{A}^{+}$. Half of those salts and ionic cocrystals contain water. Within this study, the acidity did not seem to have an impact on whether a salt or ionic cocrystal is formed or whether water forms part of the 
crystalline structure. For example, the strongest acid (perchloric acid) formed an ionic cocrystal whilst a weaker acid, phthalic acid, formed a salt. The formation of ionic cocrystals versus salts, in our case, seem to be governed by stoichiometry and the nature of the solvent used (see ESI). Finally, of the four cocrystals known with acids and reported in Table 4, three of them contain tautomer B whilst one of them (with benzoic acid) contains tautomer A.

\subsection{Analysis of AHMP Salts}

The various salts obtained during our screening had some structural similarities. Most of these salts showed a catermeric head to tail motif (Figure 5a) involving the $\mathrm{A}^{+}$cation with various degree of counterion insertion (Figure 5). Some counterions preferentially interacted with the $\mathrm{N} 1-\mathrm{H}$ (nitrogen adjacent to the $\mathrm{C}=\mathrm{O}$ group), for example as in the oxalate salt (Figure 5a); whilst others interacted with both $\mathrm{N} 1 \mathrm{H}$ and $\mathrm{N} 3 \mathrm{H}$, as in the $\mathrm{HCl}$ and phthalate salts (Figure $5 \mathrm{~b}$ and c).

a)

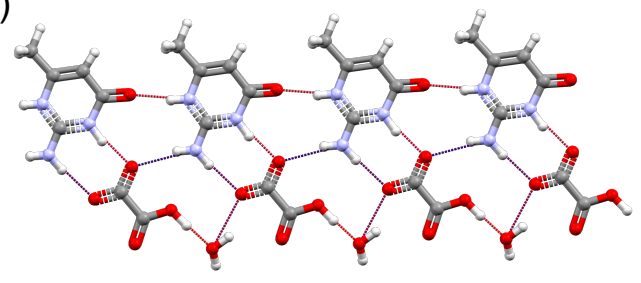

b)

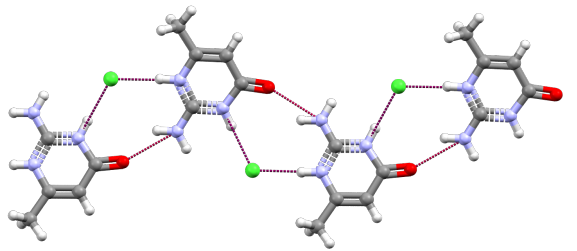

c)

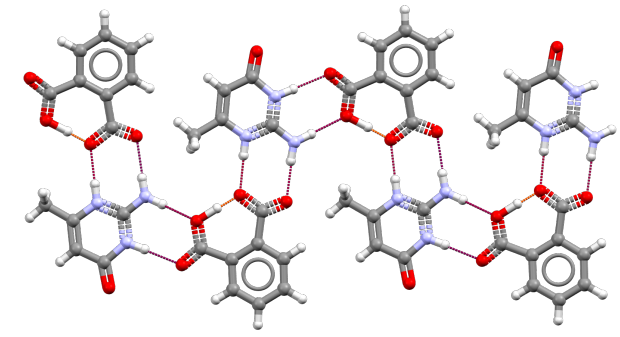

Figure 5. Catemeric motifs found in a) hydrate of $\mathrm{A}^{+}$:Oxalate salt, b) $\mathrm{A}^{+}: \mathrm{Cl}^{-}$salt and c) $\mathrm{A}^{+}$:phthalate salt.

Most interestingly in the saccharin salt hydrate, we obtained polymorphs which arise from synthon polymorphism (Figure 6). The two forms crystallised concomitantly from water by 
slow evaporation. Form I, cube-like crystals, were collected from the bottom of the flask whilst form II, plate-like crystals, were found floating on the surface of solution. In form I, the saccharin $\mathrm{H}$-bonds to the $\mathrm{A}^{+} \mathrm{N} 1 \mathrm{H}$ whilst in form II the saccharin interacts with the $\mathrm{A}^{+}$ N2H (Figure 6).
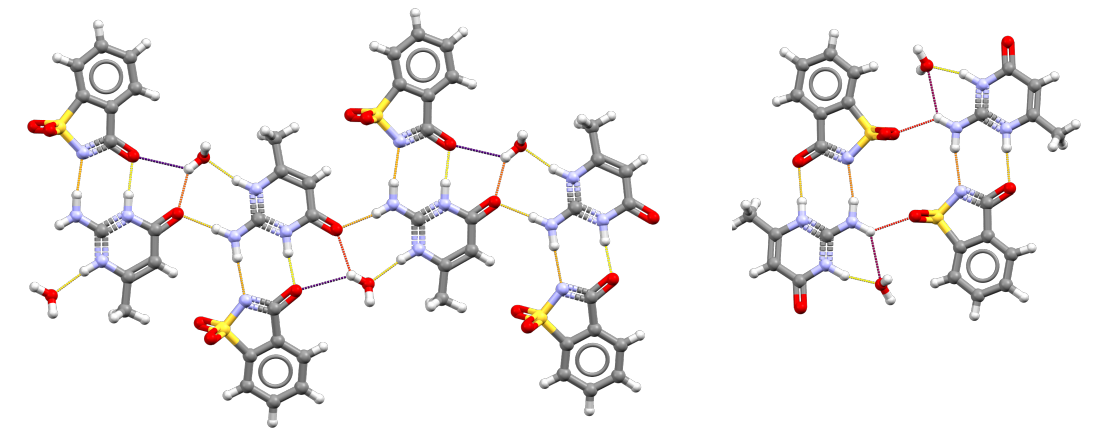

Figure 6. H-bonding in the structures of forms I (left) and II (right) $\mathrm{A}^{+}$:saccharin salt hydrate.

\subsection{Analysis of AHMP Ionic Cocrystals}

All of the ionic cocrystals of AHMP contained the strong $\mathrm{A}: \mathrm{B}^{+}$dimer sustained through three very stable $\mathrm{H}$-bonds (Figure 7). The free $\mathrm{N} 3 \mathrm{H}$ of the $\mathrm{A}: \mathrm{B}^{+}$dimer, then interacts through H-bonds with either the salt counterions (Figure 7a) or water in the case of the hydrated ionic cocrystals (Figure 7b). We note that the AHMP ionic cocrystal with $\mathrm{HCl}$ has a high degree of disorder and a very unusual stoichiometry $\left(\mathrm{A}: \mathrm{B}^{+}: \mathrm{X}^{-}: \mathrm{W}, 3: 1: 1: 5\right)$ the image in Figure $7 \mathrm{~b}$ being an idealised model. Further information on this structure is given in the ESI.

a) Ionic Cocrystals

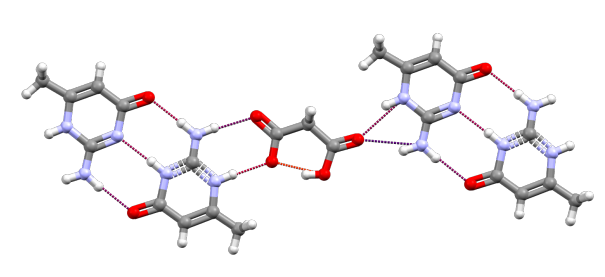

b) Hydrates of Ionic Cocrystals
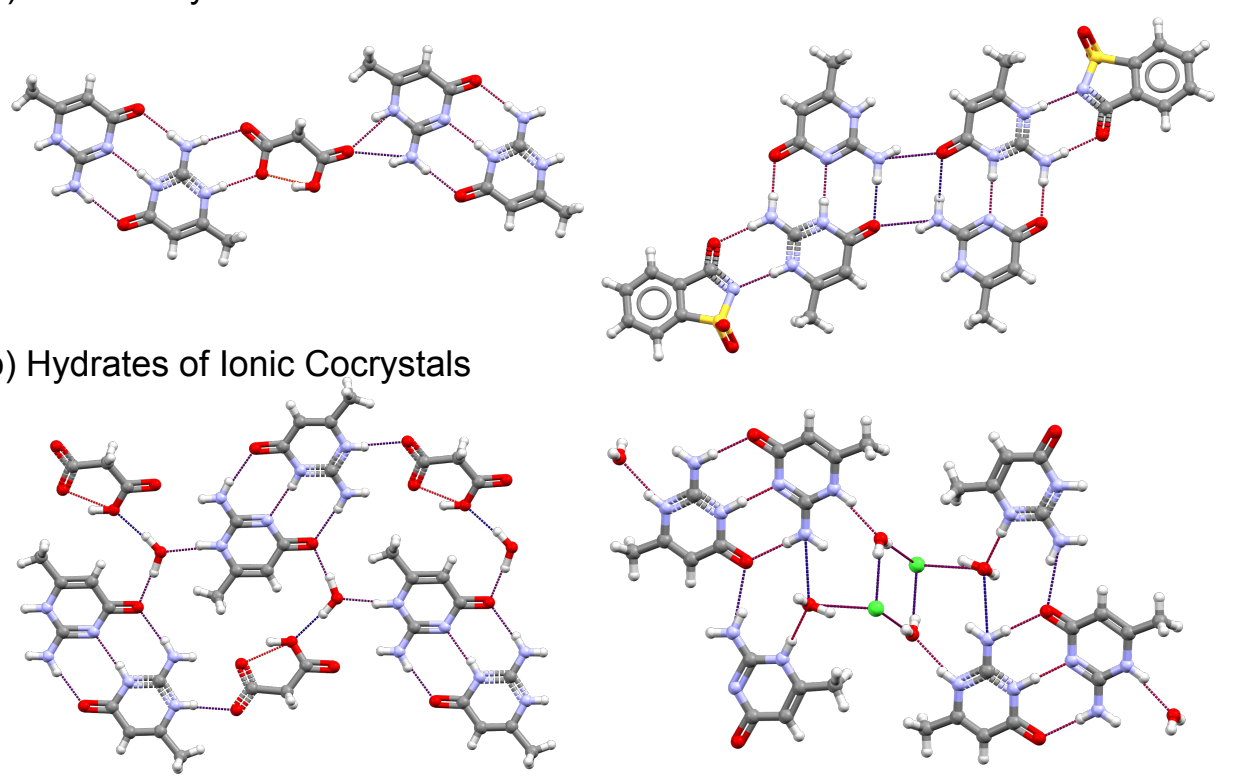

Figure 7. Strong $\mathrm{A}: \mathrm{B}^{+}$dimers and $\mathrm{H}$-bonding between dinmers and salt counterions or water in the structures of (a) ionic cocrystals and (b) hydrates of ionic cocrystals discovered in this 
study.

\subsection{Analysis of Cocrystals}

Of the cocrystals obtained in this study, two of them contained the B tautomer whilst one contained the A tautomer (Figure 8). The dominance of the B tautomer was expected as it is the lowest energy tautomer. The H-bonding in the A:benzoic acid cocrystal consists of a head to tail AHMP catemer: the benzoic acid coformer hydrogen bonds to the $\mathrm{N} 1$ and the $\mathrm{NH}_{2}$. In the B tautomer cocrystals, however, B:B dimers are formed and the acids hydrogen bond to the $\mathrm{N} 3$ nitrogen and the $\mathrm{NH} 2$.

The cocrystal with p-aminobenzoic acid showed disorder in the position of the acid proton as inferred from SCXRD at low temperature. However, XPS analysis of this sample at room temperature, confirmed that the species present in the structure was unequivocally tautomer B (see next section).

a) A Tautomer

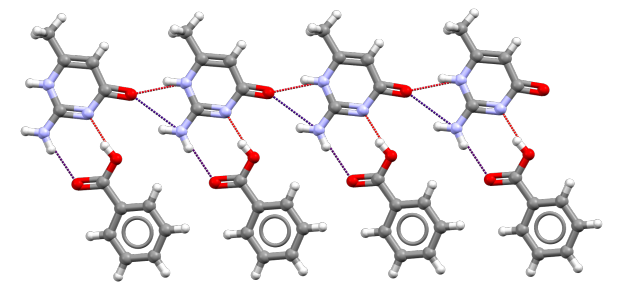

b) B Tautomer

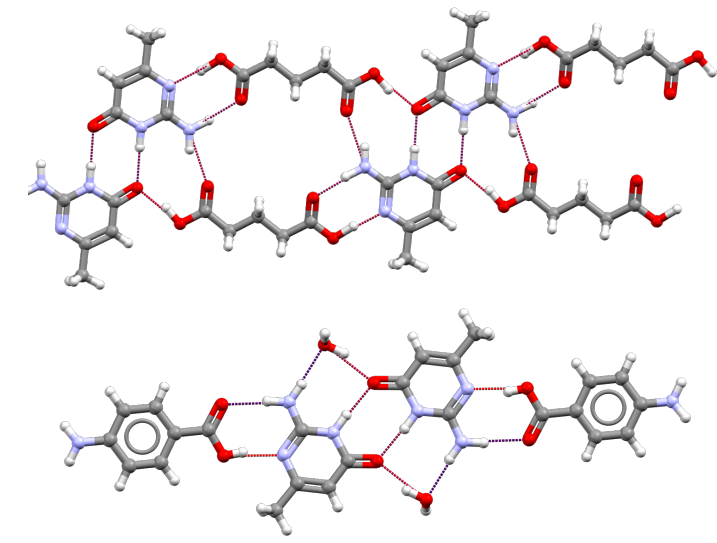

Figure 8. (a) Catemeric motifs of tautomer A and (b) B:B dimers, as well as related H-bonding in the structures of cocrystals of AHMP.

\subsection{XPS Analysis}

Given the variety of molecular forms available to AHMP through intra and inter proton migration (tautomers $\mathrm{A}, \mathrm{B}, \mathrm{C}$ and cation $\mathrm{A}^{+} / \mathrm{B}^{+}$), determining the position of the $\mathrm{H}$ atoms is 
fundamental for these structures. We used nitrogen XPS to identify the different types of N present in the structures to provide additional evidence for the crystallographic assignment of molecular species, as it is highly sensitive to the local chemical state/environment of an atom. The changes in chemical environment around the N1, N2 and N3 nitrogen atoms in the tautomeric forms, as well as in the protonated state, result in changes in the nitrogen XPS spectra. Therefore, XPS can help identify the tautomer species in solid structures, especially for products for which it is difficult to grow high quality single crystals suitable for single crystal XRD analysis. The tautomeric and protonated form of AHMP in all the multi-component products could be identified directly in the experimental samples with XPS; a representative summary of the XPS spectra for the different tautomers and cationic form is given in Figure 9, based on the experimental data for the AHMP forms analysed (see XPS results section in the ESI).

For all three neutral tautomers, the N2 environment always remains identical (C-NH2); this environment gives a signal at $399.6 \mathrm{eV}$ in all $\mathrm{A}, \mathrm{B}$ and $\mathrm{C}$ tautomers (blue component, Figure 9). In the A and B tautomers, the N1 (purple) and N3 (red) signals are different since in tautomer A N3 is protonated whilst in tautomer B N1 is protonated. For tautomer A, the N3 signal $(\mathrm{C}-\mathrm{NH}-\mathrm{C}=\mathrm{O})$ is at $400.4 \mathrm{eV}$ and the $\mathrm{N} 1(\mathrm{C}=\mathrm{N})$ is $398.5 \mathrm{eV}$ (Figure 9a), while for tautomer $\mathrm{B}$, the $\mathrm{N} 3$ signal $(\mathrm{C}=\mathrm{N})$ is at $398.9 \mathrm{eV}$ and the $\mathrm{N} 1(\mathrm{C}-\mathrm{NH}-\mathrm{C}=\mathrm{O})$ is at $400.6 \mathrm{eV}$ (Figure 9b). While the signals of tautomer A and B are similar, the variance in the relative chemical shifts of $\mathrm{N} 1$ and $\mathrm{N} 3$ from the N2 position leads to the profile of the XPS spectrum being different which allows differentiation (see glutaric acid cocrystal example in the ESI). For tautomer C, no experimental forms with tautomer $\mathrm{C}$ have been successfully obtained to date. The N1/N3 signals should be analogous since both nitrogens are in a $\mathrm{C}=\mathrm{N}$ environment and is expected to lie around $398.7 \pm 0.2 \mathrm{eV}$ (Figure 9c) based on the values observed for this type of environment in tautomers A and B; DFT confirms this, indicating only ca. $+0.1 \mathrm{eV}$ for $\mathrm{N} 1$ (relative to N3) with the nearby presence of the OH. The XPS spectrum of tautomer C is thus predicted to be quite distinct from those of $\mathrm{A}$ and $\mathrm{B}$.

With regards to the salts, protonation of AHMP to the cation results in a state in which all only a single signal is observed for three nitrogen atoms (N1, N2, N3). This results in a much narrower spectrum with a unique band at around $400.5 \mathrm{eV}$ (see $\mathrm{HCl}$ salt example in the ESI). 
Protonation of the original $\mathrm{C}=\mathrm{N}$ nitrogen results in a ca. $+2 \mathrm{eV}$ shift to higher binding energy compared to the neutral tautomers, which is in line with the characteristic chemical shift observed for protonation wih XPS protonation with XPS ${ }^{54-57}$ In addition, the single signal reflects that the positive charge becomes somewhat delocalised, as the C-NH2 is also shifted to slightly higher energy than in the neutral tauromers.
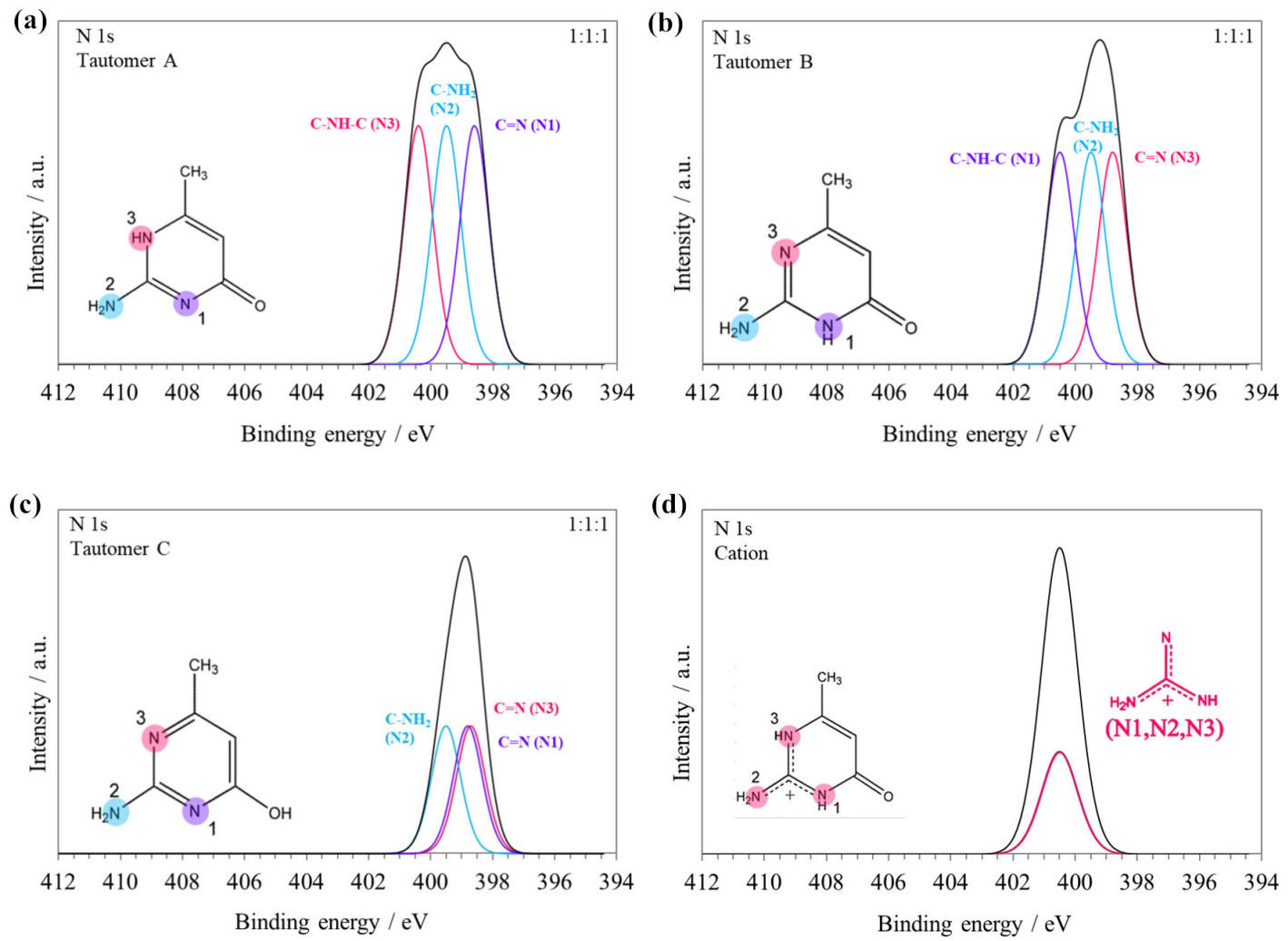

Figure 9. Schematic representation of the nitrogen XPS for the tautomeric forms A and B, the cationic form $\mathrm{A}^{+}$of AHMP (based on experimental XPS, see ESI), and that expected for the as yet unobtained tautomer $\mathrm{C}$.

First we analysed protonation state of AHMP in AHMP-pABA complex. While the single crystal XRD provided the crystal structure for AHMP:pABA, it did not provide resolution on the position of the hydrogen between AHMP and pABA and thus no assignment of whether proton transfer occurred (i.e. whether a salt or cocrystal was formed, see ESI). All of the AHMP signals in XPS occur in the positions expected for neutral tautomer B (Figure 10), revealing AHMP:pABA is a cocrystal and not a salt. 


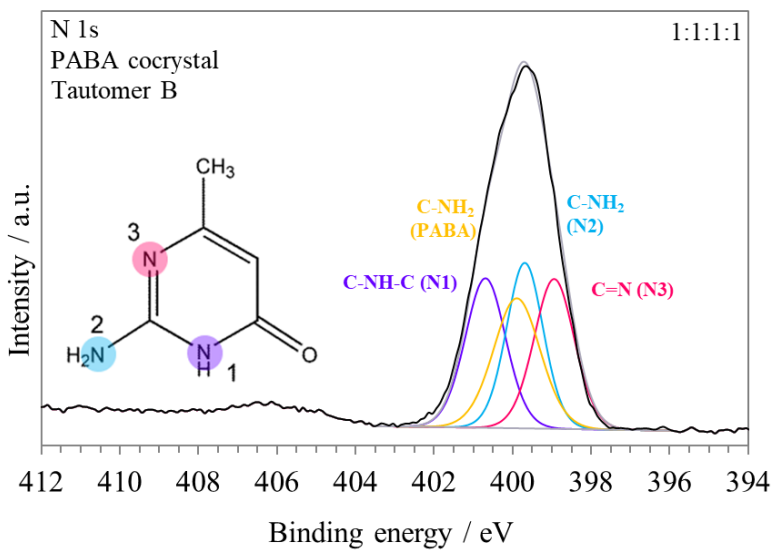

Figure 10. Nitrogen XPS of the AHMP:pABA complex $(1: 1)$.

Finally, below we analyse the XPS spectrum (Figure 11) of the A: $\mathrm{A}^{+}$:saccharin ionic cocrystal. The nitrogen XPS shows three signals at $398.5,399.4$ and $400.4 \mathrm{eV}$, in a 2:1:4 ratio. This is a combination result of one neutral, unprotonated AHMP (tautomer A) molecule, one saccharin anion and one protonated AHMP cation. The peak at $398.5 \mathrm{eV}$ arises from the $\mathrm{N}-\mathrm{SO}_{2}$ nitrogen of the saccharin anion and $\mathrm{C}=\mathrm{N}(\mathrm{N} 1)$ of neutral AHMP. The peak at $399.4 \mathrm{eV}$ is from $\mathrm{C}-\mathrm{NH}_{2}(\mathrm{~N} 2)$ of neutral AHMP, and the highest energy peak at $400.4 \mathrm{eV}$ is comprised of both the C-NH-C (N3) of neutral AHMP and the characterisitic signal of the AHMP cation $(\mathrm{N} 1 / \mathrm{N} 2 / \mathrm{N} 3)$. This is in complete agreement with the results obtained from single crystal structure analysis, a 2:1 ratio of AHMP and saccharin with one of the AHMP molecules being protonated (ionic cocrystal).

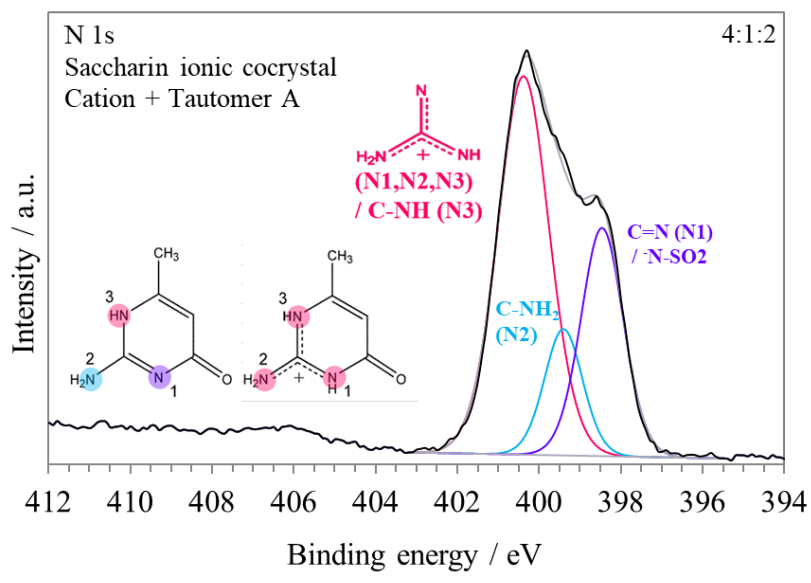

Figure 11. Nitrogen XPS of the AHMP:saccharin ionic cocrystal (2:1). 


\section{Discussion}

AHMP, a compound with two hydrogen bond donors $\left(\mathrm{NH}, \mathrm{NH}_{2}\right)$ and two hydrogen bond acceptors $(=\mathrm{N}-,=\mathrm{O})$, can display different tautomeric species with significantly different supramolecular architectures in the solid state. DFT calculations of the tautomer stabilities of AHMP revealed the following stability order $\mathrm{B}>\mathrm{A}>\mathrm{C}$ in environments other than the gas-phase. Whilst tautomers B and A have similar chemical functionalities (keto tautomers) in opposite ends of the molecule, tautomer $\mathrm{C}$ has a very different chemical nature (enol tautomer). Because of this, we attempted a selective cocrystal design for tautomers A and B with carboxylic acid coformers and for tautomer $\mathrm{C}$ with a series of imide molecules. Cocrystallisation of AHMP with the acid coformers resulted in a large number of salts, ionic cocrystals and cocrystals which were described in detail in the results section. Cocrystallisation of AHMP with the imide coformers failed and afforded no new cocrystals. Somewhat disappointingly, we were thus unable to isolate tautomer $\mathrm{C}$ in the solid state through our imide cocrystallisation strategy.

The CSD analysis and the new structures obtained in this work, revealed the following order of tautomeric prevalence in the solid state $\mathrm{B}>\mathrm{A}: \mathrm{B}>\mathrm{A}$. The experimental observations, thus, follow tautomer energy stabilities, B almost always being dominant. Interestingly, the supramolecular complementarity between $\mathrm{A}$ and $\mathrm{B}$ make cocrystals of $\mathrm{A}: \mathrm{B}$ much more common than forms containing just tautomer A. In its neat form, AHMP is found as tautomer A $(\text { FETSEC) })^{58}$ and in a A:B self-cocrystal (ZERMIS) ${ }^{51}$. Computation of motif interactions (Table 5) involving the different tautomeric species show that the dimers formed by B:B and $\mathrm{A}: \mathrm{B}$ and the $\mathrm{A}: \mathrm{A}$ head to tail interaction, are all isoenergetic in water whilst the $\mathrm{B}: \mathrm{B}$ and the A:B dimers are noticeably the most favourable in less polar enviroments. These calculations mirror well the experimental observations. For example, all experimental cocrystals containing the B tautomer display B:B dimers whilst our newly discovered cocrystal containing the A tautomer (with benzoic acid) displays a head to tail motif. Whilst we did not find any cocrystals of AHMP containig the A:B dimer, one of the polymorphs of AHMP is in fact a self-cocrystal containing them (ZERMIS) whilst three previously known solvates $\left(\right.$ MECXUP $^{38}$, OQURAU, OQUREY ${ }^{59}$ ) are also based on these dimers. However, we only 
obtained three new cocrystals. The vast majority of our cocrystallisation experiments with selected acids resulted in either salt or ionic cocrystal solid forms. All AHMP:coformer forms with $\Delta \mathrm{p} K_{\mathrm{a}}$ greater than 0 but less than 4 (the unpredictable salt-cocrystal region) resulted in charged species and no cocrystals. Furthermore, AHMP was in fact able to form both salts and ionic cocrystals with several acids, including $\mathrm{HCl}$, saccharin and phosphoric acid. The main difference between these salts and the ionic cocrystals is the stoichiometry between AHMP and the coformer, usually 1:1 in salts and 2:1 in the ionic cocrystals. The factors influencing wether a salt or an ionic cocrytal formed were a) stoichiometry and b) solvent. In most cases, stoichiometry was the principal factor. Hence, crystallisations with a 1:1 ratio of AHMP:coformer resulted in salts whilst crystallisations with a 2:1 ratio of AHMP:coformer resulted in ionic cocrystals. There was one case, however, in which the solvent played a fundamental role. Hence, when 1:1 AHMP:saccharin was crystallised from water, the hydrated ionic cocrystals polymophs were obtained whilst when the same 1:1 AHMP:saccharin stoichiometry was crystallised from methanol, the 2:1 ionic cocrystal was obtained (ESI). All salts contained the $\mathrm{A}^{+} / \mathrm{B}^{+}$cation only in a variety of motifs while all ionic cocrystals contained the $\mathrm{A}: \mathrm{B}^{+}$dimer held by three strong hydrogen bonds (one of which is also charge-assisted).

Table 5. Stability of the various motifs possible for the A and B tautomers as well as the C:glutarimide dimer. The overall stability of the motif accounts for the tautomeric energy.

\begin{tabular}{|c|c|c|c|c|}
\hline \multirow{2}{*}{ Species } & \multirow{2}{*}{ Motif } & \multicolumn{3}{|c|}{ Stability of motif (kJ/mol) } \\
\cline { 3 - 5 } & & Gas & Chloroform & Water \\
\hline B:B & Dimer & -109.3 & -59.6 & -34.2 \\
\hline A:B & Dimer & -80.9 & -54.4 & -35.0 \\
\hline A:A & Head to tail* & 41.4 & -19.0 & -34.3 \\
\hline A:A & Dimer & -8.2 & -8.6 & -13.6 \\
\hline C:glutarimide & Dimer & -86.1 & -38.6 & -14.7 \\
\hline
\end{tabular}

*Since this is a catemeric motif, it is calculated as twice the head to tail interaction.

Finally, in an attempt to rationalise why our cocrystallisation strategy of tautomer C failed, we computed the dimer stability of $\mathrm{C}$ with glutarimide (Table 5). Whilst, as anticipated, the C:imide dimer is very stable $(-80.9 \mathrm{~kJ} / \mathrm{mol})$, it is only competitive in the gas-phase. As the tautomer relative energy increases in more polar environments from $0-20 \mathrm{~kJ} / \mathrm{mol}$ (Table 3), 
the $\mathrm{C}$ :imide motif becomes uncompetitive compared to the other possible motifs. We notice that tautomer $\mathrm{C}$ has never been observed in the CSD before (with the exception of two structures which contain errors, thus wrongly assined tautomer C) and that our attempt to isolate it via cocrystallisation has also failed. Thus, isolation of the enol tautomer for AHMP and other molecules containing this ring substructure remains an open challenge.

\section{Conclusions}

We have explored cocrystallisation of a relatively "simple" compound, AHMP, with a series of acids and imides. Because AHMP is able to tautomerise and is basic, our solid form explorations have resulted in an interesting variety of new solid forms including salts, cocrystals and ionic cocrystals containing several tautomers (A, B, A:B) and a cationic form $\left(\mathrm{A}^{+}\right)$.

The new salts all contained the same molecular species and a variety of supramolecular motifs. The ionic cocrystals all contained a very stable $\mathrm{A}: \mathrm{B}^{+}$dimer. It was surprising how easy it was to form ionic cocrystals with this compound driven by the strong supramolecular complementarity between $\mathrm{A}$ and $\mathrm{B}^{+}$. With recent interest in developing ionic cocrystals because of their potential physicochemical advantages, ${ }^{60,61}$ molecules containing pyrimidinone substructures such as AHMP can serve as model systems for ionic cocrystals. In this system, formation of an ionic cocrystal instead of a salt was entirely dominated by the stoichiometry available in solution. In fact, in many cases, formation of both salts and cocrystals were possible. Cocrystals of AHMP contained either tautomer B (majority) or A and previously known solvates of AHMP contained A:B dimers. Our design strategy to crystallise tautomer C (enol tautomer) in the form of cocrystals with imide coformers failed. We rationalized this with the aid of DFT calculations; whilst our synthon C:imide hypothesis was a competitive one in a gas-phase environment, it proved to be unstable in polar environments. Finally, we have employed XPS as a complementary technique to XRD which has helped us in the unambiguous determination of the tautomers and protonation species present in our AHMP salts, cocrystals and ionic cocrystals.

\section{Acknowledgements}


AJCC thanks the Royal Society for support through a Royal Society Industry Fellowship. TV thanks the Royal Academy of Engineering for support through an Engineering for Development research fellowship. TW thanks the China Scholarship Council for financial support.

\section{Supporting Information}

The supporting information is available free of charge on the ACS Publications website at DOI: $\mathrm{xxx}$.

Experimental details on the grinding and crystallizations; PXRD, DSC and TGA of the new solid forms obtained; titration curve for $\mathrm{pK}_{\mathrm{a}}$ determination; single crystal XRD data and structure analysis for the new forms; detailed analysis of the disorder in the AHMP ionic cocrystal hydrate with $\mathrm{HCl}$; XPS patterns for the new forms.

\section{References}

(1) Vangala V R, Chow P S, Tan R B H. "Co-crystals and co-crystal hydrates of the antibiotic nitrofurantoin: structural studies and physicochemical properties.” Cryst. Growth Des. 2012, 12, 5925-5938

(2) Sokal, A., Pindelska, E., Szeleszczuk, L., Kolodziejski, W. "Pharmaceutical properties of two ethenzamide-gentisic acid cocrystal polymorphs: Drug release profiles, spectroscopic studies and theoretical calculations.” Int. J. Pharm. 2017, 522, 80-89.

(3) Svärd, M., Valavi, M., Khamar, D., Kuhs, M., Rasmuson, Å. C. “Thermodynamic stability analysis of tolbutamide polymorphs and solubility in organic solvents.” J. Pharm. Sci. 2016, 105, 1901-1906.

(4) Liu, J., Svärd, M., Hippen, P., Rasmuson, Å. C. "Solubility and crystal nucleation in organic solvents of two polymorphs of curcumin.” J. Pharm. Sci. 2015, 104, 2183-2189.

(5) Mishra, M. K., Sanphui, P., Ramamurty, U., Desiraju, G. R. "Solubility-hardness correlation in molecular crystals: curcumin and sulfathiazole polymorphs." Cryst. Growth Des. 2014, 14, 3054-3061.

(6) Almarsson Ö, Zaworotko M J. "Crystal engineering of the composition of pharmaceutical phases. Do pharmaceutical co-crystals represent a new path to improved medicines?" Chem. Commun. 2004, 1889-1896.

(7) Vishweshwar, P., McMahon, J. A., Bis, J. A., Zaworotko, M. J. “Pharmaceutical co-crystals.” J. Pharm. Sci. 2006, 95, 499-516.

(8) Blagden, N., Berry, D. J., Parkin, A., Javed, H., Ibrahim, A., Gavan, De Matos, L.L., P. T., Seaton, C. C. “Current 
directions in co-crystal growth.” New J. Chem. 2008, 32, 1659-1672.

(9) Delori A, Friščić T, Jones W. "The role of mechanochemistry and supramolecular design in the development of pharmaceutical materials." CrystEngComm. 2012, 14, 2350-2362.

(10) Rajput L, Sanphui P, Desiraju G R. "New solid forms of the anti-HIV drug etravirine: salts, cocrystals, and solubility." Cryst. Growth Des. 2013, 13, 3681-3690.

(11) Aakeröy C B. “Crystal engineering: strategies and architectures.” Acta Crystallogr., Sect. B: Struct. Sci. 1997, 53, $569-586$.

(12) Aakeröy C B, Forbes S, Desper J. "Using cocrystals to systematically modulate aqueous solubility and melting behavior of an anticancer drug.” J. Am. Chem. Soc.2009, 131, 17048-17049.

(13) Fábián L. "Cambridge structural database analysis of molecular complementarity in cocrystals.” Cryst. Growth Des. 2009, 9, 1436-1443.

(14) Childs S L, Stahly G P, Park A. "The salt- cocrystal continuum: the influence of crystal structure on ionization state.” Mol. Pharmaceutics. 2007, 4, 323-338.

(15) Braga, D., Grepioni, F., Lampronti, G. I., Maini, L., Turrina, A. "Ionic co-crystals of organic molecules with metal halides: A new prospect in the solid formulation of active pharmaceutical ingredients.” Cryst. Growth Des. 2011, 11, 5621-5627.

(16) Cruz-Cabeza, A. J. “Acid-base crystalline complexes and the pKa rule.” CrystEngComm. 2012, 14, 6362-6365.

(17) Aakeroy, C. B.; Fasulo, M. E.; Desper. “Cocrystal or salt: does it really matter?” J. Mol. Pharmaceutics. 2007, 4, 317-322

(18) Childs, S. L.; Stahly, G. P.; Park, "The salt-cocrystal continuum: the influence of crystal structure on ionization state.” A. Mol. Pharmaceutics. 2007, 4, 323-338.

(19) da Silva, C. C., Pepino, R. D. O., de Melo, C. C., Tenorio, J. C., Ellena, J. “Controlled Synthesis of New 5-Fluorocytosine Cocrystals Based on the pKa Rule.” Cryst. Growth Des. 2014, 14, 4383-4393.

(20) Elacqua, E., Bučar, D. K., Henry, R. F., Zhang, G. G., MacGillivray, L. R. "|Supramolecular complexes of sulfadiazine and pyridines: reconfigurable exteriors and chameleon-like behavior of tautomers at the co-crystal-salt boundary." Cryst. Growth Des. 2012, 13, 393-403.

(21) Delaney, S. P., Witko, E. M., Smith, T. M., Korter, T. M. "Investigating tautomeric polymorphism in crystalline anthranilic acid using terahertz spectroscopy and solid-state density functional theory.” J. Phys. Chem. A. 2012, 116, 8051-8057.

(22) Galvão, T. L., Rocha, I. M., Ribeiro da Silva, M. D., Ribeiro da Silva, M. A. "From 2-hydroxypyridine to 4 (3 H)-pyrimidinone: computational study on the control of the tautomeric equilibrium.” J. Phys. Chem. A. 2013, 117, 12668-12674. 
(23) Martin Y C. “Let's not forget tautomers.” J. Comput. Aided Mol. Des. 2009, 23, 693.

(24) Desiraju G R. "Intermolecular proton transfers in the solid state. Conversion of the hydroxyazo into the quinone hydrazone tautomer of 2-amino-3-hydroxy-6-phenylazopyridine. X-Ray crystal structures of the two forms.” J. Chem. Soc., Perkin Trans. 2, 1983, 1025-1030.

(25) Wang, L., Luo, M., Li, J., Wang, J., Zhang, H., Deng, Z. "Sweet theophylline cocrystal with two tautomers of acesulfame.” Cryst. Growth Des. 2015, 15, 2574-2578.

(26) Juribašić, M., Bregović, N., Stilinović, V., Tomišić, V., Cindrić, M., Šket, P., Plavec, J., Rubčić, M., Užarević, K. "Supramolecular stabilization of metastable tautomers in solution and the solid state." Chem. Eur. J. 2014, 20, $17333-17345$.

(27) Ghosh S, Bag P P, Reddy C M. "Co-crystals of sulfamethazine with some carboxylic acids and amides: Co-former assisted tautomerism in an active pharmaceutical ingredient and hydrogen bond competition study.” Cryst. Growth Des. 2011, 11, $3489-3503$.

(28) Cruz-Cabeza A J, Groom C R. "Identification, classification and relative stability of tautomers in the cambridge structural database." CrystEngComm. 2011, 13, 93-98.

(29) Childs S L, Hardcastle K I. “Cocrystals of piroxicam with carboxylic acids.” Cryst. Growth Des. 2007, 7, $1291-1304$.

(30) Lu, J., Cruz-Cabeza, A. J., Rohani,S., Jennings,M.C. “A 2: 1 sulfamethazine-theophylline cocrystal exhibiting two tautomers of sulfamethazine.” Acta Crystallogr., Sect. C: Cryst. Struct. Commun. 2011, 67, o306-o309.

(31) Bhatt P M, Desiraju G R. “Tautomeric polymorphism in omeprazole.” Chem. Commun. 2007, 2057-2059.

(32) Schmidt, M. U., Brüning, J., Glinnemann, J., Hützler, M. W., Mörschel, P., Ivashevskaya, S. N., van de Streek, J., Braga, D., Maini, L., Chierotti, M., Gobetto, R. "The thermodynamically stable form of solid barbituric acid: the enol tautomer." Angew. Chem. Int. Ed. 2011, 50, 7924-7926.

(33) Elacqua, E., Bučar, D. K., Henry, R. F., Zhang, G. G., MacGillivray, L. R. "Supramolecular complexes of sulfadiazine and pyridines: reconfigurable exteriors and chameleon-like behavior of tautomers at the co-crystal-salt boundary." Cryst. Growth Des. 2012, 13, 393-403.

(34) Desiraju G R. "Supramolecular synthons in crystal engineering — a new organic synthesis.” Angew. Chem. Int. Ed. 1995, $34,2311-2327$.

(35) Wales C, Thomas L H, Wilson C C. "Tautomerisation and polymorphism in molecular complexes of piroxicam with mono-substituted benzoic acids.” CrystEngComm., 2012, 14, 7264-7274.

(36) Tilborg, A., Springuel, G., Norberg, B., Wouters, J., Leyssens, T. "How Cocrystallization Affects Solid-State Tautomerism: Stanozolol Case Study.” Cryst. Growth Des. 2014, 14, 3408-3422. 
(37) Gilli G, Bertolasi V, Gilli P. "Solid-State N-H• O/O-H• N Tautomerism in Resonance-Assisted 1-(Arylazo)-2-Naphthols and Its Through-Space $\pi^{*} \leftarrow \pi$ Perturbation in TCNQ Cocrystals. A Variable-Temperature X-ray Crystal Study.” Cryst. Growth Des. 2013, 13, 3308-3320.

(38) Tutughamiarso M, Egert E. “Cocrystals of 5-fluorocytosine. II. Coformers with variable hydrogen-bonding sites.” Acta Crystallogr. Sect. B: Struct. Sci. 2012, 68, 444-452.

(39) Epa, K., Aakeröy, C. B., Desper, J., Rayat, S., Chandra, K. L., Cruz-Cabeza, A. J. “Controlling molecular tautomerism through supramolecular selectivity." Chem. Commun. 2013, 49, 7929-7931.

(40) Karthikeyan, A., Swinton Darious, R., Thomas Muthiah, P., Perdih, F. "Supramolecular hydrogen-bonding patterns in two cocrystals of the N (7)-H tautomeric form of N6-benzoyladenine: N6-benzoyladenine-

3-hydroxypyridinium-2-carboxylate (1/1) and N6-benzoyladenine-dl-tartaric acid (1/1).” Acta Crystallogr., Sect. C: Cryst. Struct. Commun. 2015, 71, 985-990.

(41) Rigaku Oxford Diffraction, (2018), CrysAlisPro Software system, version 1.171.39.46, Rigaku Corporation, Oxford, UK

(42) G.M. Sheldrick (2015) "Crystal structure refinement with SHELXL", Acta Cryst., C71, 3-8 (Open Access)

(43) Stevens, J. S.; Schroeder, S. L. M., “Quantitative Analysis of Saccharides by X-ray Photoelectron Spectroscopy. Surf. Interface Anal.” 2009, 41, 453-462.

(44) Fairley, N.; Carrick, A., “The Casa Cookbook - Part 1: Recipes for XPS Data Processing.” Acolyte Science: Knutsford, Cheshire, 2005.

(45) Frisch M. J., Trucks G. W., Schlegel H. B., Scuseria G. E., Robb M. A., Cheeseman J. R., Scalmani G., Barone V., Mennucci B., Petersson G. A., et al. Gaussian 09, Revision B.01. Inc., Wallingford, CT, 2010, 6492.

(46) Stevens, J. S.; Gainar, A.; Suljoti, E.; Xiao, J.; Golnak, R.; Aziz, E. F.; Schroeder, S. L. M., "Chemical Speciation and Bond Lengths of Organic Solutes by Core Level Spectroscopy: pH- and Solvent-Influence on p-Aminobenzoic Acid.” Chem. - Eur. J. 2015, 21, 7256-7263.

(47) GaussView, Version 5. Roy Dennington, Todd Keith, and John Millam ed.; R. Dennington, T. Keith, and J. Millam, Semichem Inc., Shawnee Mission, KS: 2009.

(48) Marenich A V, Cramer C J, Truhlar D G. "Universal solvation model based on solute electron density and on a continuum model of the solvent defined by the bulk dielectric constant and atomic surface tensions.” J. Phys. Chem. 2009, 113, 6378-6396.

(49) Haschemeyer A E V, Sobell H M. "The crystal structure of a hydrogen bonded complex of deoxyguanosine and 5bromodeoxycytidine." Acta Crystallogr. 1965, 19, 125-130.

(50) P.Karen, R.L.Harlow, Zhigang Li, P.Meenan, P.A.Parziale. "The Crystal Structure of 2-Amino-4, 6-dihydroxypyrimidine 
Determined from Powder X-Ray Synchrotron Diffraction.” Acta Chem.Scand. 1998,52,1051-1055.

(51) Toledo L M, Musa K, Lauher J W, Fowler, F. W. "Development of Strategies for the Preparation of Designed Solids. An Investigation of the 2-Amino-4 (1H)-pyrimidone Ring System for the Molecular Self-Assembly of Hydrogen Bonded. alpha.-and. beta.-Networks.” Chem. Mater. 1995, 7,1639-1647.

(52) Vishweshwar P, Nangia A, Lynch V M. "Recurrence of carboxylic acid- pyridine supramolecular synthon in the crystal structures of some pyrazinecarboxylic acids”. J.Org.Chem., 2002, 67(2): 556-565.

(53) Liao R F, Lauher J W, Fowler F W. "The application of the 2-amino-4-pyrimidones to supramolecular synthesis.” Tetrahedron, 1996, 52, 3153-3162.

(54) Stevens, J. S.; Byard, S. J.; Schroeder, S. L. M., "Salt or Co-Crystal? Determination of Protonation State by X-ray Photoelectron Spectroscopy (XPS).”J. Pharm. Sci. 2010, 99, 4453-4457.

(55) Stevens, J. S.; Byard, S. J.; Seaton, C. C.; Sadiq, G.; Davey, R. J.; Schroeder, S. L. M., “Crystallography Aided by Atomic Core-Level Binding Energies: Proton Transfer Versus Hydrogen Bonding in Organic Crystal Structures.” Angew. Chem., Int. Ed. 2011, 50, 9916-9918.

(56) Stevens, J. S.; Byard, S. J.; Seaton, C. C.; Sadiq, G.; Davey, R. J.; Schroeder, S. L. M., "Proton Transfer and Hydrogen Bonding in the Organic Solid State: A Combined XRD/XPS/ssNMR Study of 17 Organic Acid-Base Complexes.” Phys. Chem. Chem. Phys. 2014, 16, 1150-1160.

(57) Stevens, J. S.; Luca, A. C. d.; Pelendritis, M.; Terenghi, G.; Downes, S.; Schroeder, S. L. M., "Quantitative analysis of complex amino acids and RGD peptides by X-ray photoelectron spectroscopy (XPS).” Surf. Interface Anal. 2013, 45, $1238-1246$.

(58) Lowe P R, Schwalbe C H, Williams G J B. "Structure of 6-methylisocytosine.” Acta Crystallogr., Sect. C: Cryst. Struct. Commun. 1987, 43(2): 330-333.

(59) Gerhardt V, Tutughamiarso M, Bolte M. "Pseudopolymorphs of 2, 6-diaminopyrimidin-4-one and 2-amino-6-methylpyrimidin-4-one: one or two tautomers present in the same crystal.” Acta Crystallogr., Sect. C: Cryst. Struct. 2011, 67(5): o179-o187.

(60) Smith A J, Kim S H, Duggirala N K, et al. "Improving lithium therapeutics by crystal engineering of novel ionic cocrystals." Mol. Pharmaceutics. 2013, 10(12): 4728-4738.

(61) Duggirala, N. K., Smith, A. J., Wojtas, Ł., Shytle, R. D., Zaworotko, M. J. "Physical stability enhancement and pharmacokinetics of a lithium ionic cocrystal with glucose.” Cryst. Growth Des. 2014, 14, 6135-6142. 


\section{For Table of Contents Use Only}

Salts, Cocrystals and Ionic Cocrystals of a "Simple" Tautomeric Compound

Ting Wang, Joanna S. Stevens, Thomas Vetter, George F. S. Whitehead, Iñigo J. Vitorica-Yrezabal, Hongxun Hao, Aurora J. Cruz-Cabeza*

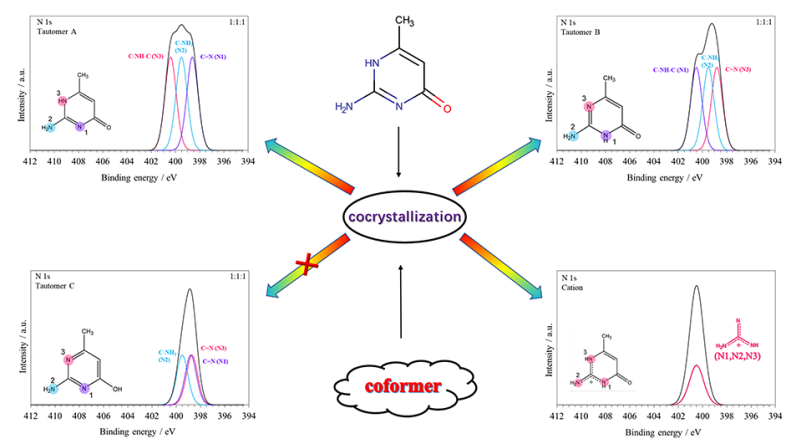

We report new salts, cocrystals and ionic cocrystals of a small molecule able to tautomerise.

The strong hydrogen bond complementarity between one of the neutral tautomers and its cationic form results in the observation of many ionic cocrystals. 